\title{
Factors associated with weaning practices in term infants: a prospective observational study in Ireland
}

\author{
Roslyn C. Tarrant ${ }^{1}$, Katherine M. Younger ${ }^{1}$, Margaret Sheridan-Pereira ${ }^{2}$, Martin J. White ${ }^{2}$ \\ and John M. Kearney ${ }^{1 *}$ \\ ${ }^{1}$ School of Biological Sciences, Dublin Institute of Technology, Kevin Street, Dublin 8, Republic of Ireland \\ ${ }^{2}$ The Department of Paediatrics, The Coombe Women and Infants University Hospital, Dublin 8, Republic of Ireland
}

(Received 12 January 2010 - Revised 12 May 2010 - Accepted 20 May 2010 - First published online 5 July 2010)

The WHO (2001) recommends exclusive breast-feeding and delaying the introduction of solid foods to an infant's diet until 6 months postpartum. However, in many countries, this recommendation is followed by few mothers, and earlier weaning onto solids is a commonly reported global practice. Therefore, this prospective, observational study aimed to assess compliance with the WHO recommendation and examine weaning practices, including the timing of weaning of infants, and to investigate the factors that predict weaning at $\leq 12$ weeks. From an initial sample of 539 pregnant women recruited from the Coombe Women and Infants University Hospital, Dublin, 401 eligible mothers were followed up at 6 weeks and 6 months postpartum. Quantitative data were obtained on mothers' weaning practices using semi-structured questionnaires and a short dietary history of the infant's usual diet at 6 months. Only one mother $(0 \cdot 2 \%)$ complied with the WHO recommendation to exclusively breastfeed up to 6 months. Ninety-one $(22.6 \%)$ infants were prematurely weaned onto solids at $\leq 12$ weeks with predictive factors after adjustment, including mothers' antenatal reporting that infants should be weaned onto solids at $\leq 12$ weeks, formula feeding at 12 weeks and mothers' reporting of the maternal grandmother as the principal source of advice on infant feeding. Mothers who weaned their infants at $\leq 12$ weeks were more likely to engage in other sub-optimal weaning practices, including the addition of non-recommended condiments to their infants' foods. Provision of professional advice and exploring antenatal maternal misperceptions are potential areas for targeted interventions to improve compliance with the recommended weaning practices.

Maternal weaning practices: Timing of weaning: Solid foods: Infant diets: Dietary patterns: Infant nutrition

The gradual introduction of solid foods, known as the 'weaning process' (or complementary feeding), is essential to provide for the increasing nutritional requirements during an infant's first year ${ }^{(1,2)}$. The $\mathrm{WHO}^{(3)}$ and the Department of Health and Children in Ireland ${ }^{(4)}$ recommend exclusive breast-feeding during the first 6 months postpartum, with the introduction of solids at 6 months. Despite this $\mathrm{WHO}^{(3)}$ recommendation, global debate over the optimal weaning age continues to challenge whether 4,6 months or a window between these two time points should be taken as the optimal age for introducing solids to an infant's diet ${ }^{(5,6)}$. While 'demand weaning' challenges the notion that there may not be a particular age for introducing solids to an infant's diet ${ }^{(6)}$, this concept has gathered momentum in the years following the introduction of advice by WHO in $2001^{(3)}$ to delay weaning to 6 months postpartum, and after the completion of the present study (after 2006). However, in Ireland, and in line with guidance from the European Society for Paediatric Gastroenterology, Hepatology and Nutrition $^{(7)}$, the consensus that the earliest introduction of solids should not be done before 4 months or 17 weeks remains an unchanged recommendation currently ${ }^{(8)}$.
The deleterious short- and long-term health implications of both early and delayed weaning are well documented. Early weaning onto solids has been associated with increased risk of allergy ${ }^{(9,10)}$, eczema ${ }^{(11,12)}$ and enteritis ${ }^{(13)}$. Weaning at $\leq 12$ weeks has been shown to increase the incidence of respiratory illness in infants aged 14-26 weeks and persistent cough at 27-39 weeks $^{(12)}$. There is also some evidence to suggest that early introduction to solid foods may result in increased percentage body fat in childhood ${ }^{(14)}$. Conversely, weaning infants beyond the recommended time may deleteriously affect the feeding behaviour ${ }^{(15)}$, and may lead to nutritional deficiencies ${ }^{(16)}$ and failure to thrive ${ }^{(17)}$.

Considering the international recommendation to initiate weaning at 6 months ${ }^{(3)}$, studies from the $\mathrm{UK}^{(18,19)}$, Belgium $^{(20)}$ and Sweden ${ }^{(21)}$ highlight that a large proportion of infants are prematurely weaned at $<4$ months of age; however, few studies have examined the reasons and risk factors for early weaning.

In addition to the importance of the timing of weaning, compliance with the recommended weaning practices can prevent certain nutritional issues in healthy term infants, including fussy eating, faltering growth, constipation and

Abbreviation: PHN, public health nurse.

* Corresponding author: Dr J. M. Kearney, fax +353 1402 4995, email john.kearney@dit.ie 
Fe-deficiency anaemia ${ }^{(22)}$. Furthermore, as early dietary patterns and feeding behaviours formed in infancy can determine childhood feeding habits and food preferences $(23,24)$ and as they have been implicated in the development of childhood overweight and obesity ${ }^{(14,25)}$, both the types of foods consumed by infants and weaning practices deserve greater attention.

Monitoring infant feeding practices, particularly since the introduction of advice by $\mathrm{WHO}^{(3)}$ to delay weaning to 6 months, is essential if targeted interventions to improve services are to be provided in an effective and structured manner ${ }^{(8)}$. However, the extent to which mothers in Ireland adhere to weaning recommendations is not known. Thus, the objectives of the present study were to examine the weaning practices of mothers in Ireland at 6 months postpartum, to establish the timing of weaning and to identify the factors predicting, or associated with early weaning.

\section{Subjects and methods}

This prospective, observational study involved the recruitment of pregnant women from the Coombe Women and Infants University Hospital (CWIUH) in west Dublin (Ireland), which is one of the three maternity hospitals in the Dublin region. Details of the methods and representativeness of the sample have been reported elsewhere ${ }^{(26)}$. Briefly, between June 2004 and October 2006, 539 pregnant women at $\geq 24$ weeks gestational age who attended either public or private/ semi-private antenatal clinics were invited to participate in the study. From the 491 women who agreed to participate (91\% recruitment rate) and of those who delivered a healthy, singleton, term infant at $\geq 37$ weeks gestational age, 483 $(98 \%)$ women were subsequently followed up at 6 weeks and $454(92 \%)$ women were followed up at 6 months postpartum. Following the application of inclusion criteria at the 6-month follow-up, including mothers who were living in Ireland and those who were willing to participate in the follow-up, 401 Irish national mothers were included in the final sample. Ethical approval for the present study was obtained from the Dublin Institute of Technology and the CWIUH Research Committees, and informed written consent was given by all the mothers.

Pre-pilot tested semi-structured questionnaires were used at each of the three contact points with mothers exclusively. The first contact point involved the completion of a subjectcompleted questionnaire, which aimed to elicit information on maternal/paternal socio-economic data, as well as specific enquiry about the age (week) at which an infant should be introduced to solid foods. The first questionnaire also collected data on mothers' smoking and alcohol status during pregnancy, including smokers $v$. non-smokers, number of cigarettes smoked/d, alcohol consumers $v$. non-alcohol consumers, number of alcohol units consumed/week. Obstetric details pertaining to the birth, including type of delivery, gestational age and health status of the infants at birth, were documented from the mothers' medical notes. Characteristics of the infants (sex, birth weight, and health status after birth) were recorded from the infants' medical notes. The 6-week and 6-month interviewer-administered surveys were conducted via telephone or face to face by a trained paediatric dietitian. The average duration of the 6-month survey interview was between 20 and $30 \mathrm{~min}$, and during this time period, information was collected on timing of weaning and practices, including additions to infants' weaning foods (multiple response options that were given included ordinary gravy, baby gravy, salted/unsalted butter, non-infant-specific sauces, sugar/honey, vegetable stock and table salt), and maternal sources of advice on infant feeding from 6 weeks to 6 months (open-ended responses which were then categorised).

Using a non-prompted open-ended question on mothers' reasons for initiating weaning, specific and individual 'reasons' were collected, which were then entered singly into the database as per mothers' responses, e.g. 'the infant was hungry all the time and not satisfied with milk alone', 'complied with weaning recommendations', 'breast milk supply was decreasing, so had to introduce solids' and 'maternal perception that the infant was a big baby and needed more than milk'. Mothers could give more than one reason for initiating weaning, e.g. infant hunger and infant sleep promotion. Cross-tabulations between each of the individually entered 'reasons for introducing solids' and the dichotomous variable 'weaned at $\leq 12$ weeks/ $>12$ weeks' were then performed. Only the reasons for initiating weaning that were statistically significant were presented.

Dietary information was obtained via maternal reporting of a short dietary history of the infant's usual diet. For infants who were consuming formula milk, data were collected on the feeding frequency $/ 24 \mathrm{~h}$ as well as on the volume of milk consumed per feed and in a $24 \mathrm{~h}$ period. As food frequency components of the dietary assessment, data pertaining to the frequency of infants' usual snack consumption per week were recorded. Data were also obtained on the daily volumes and type of supplementary fluids consumed by the infants.

\section{Explanatory measures}

The following weaning practices were examined:

1. Age (weeks) at the introduction of solid foods. Solid foods, or solids, were defined as any food offered to the infants other than their main milk drink. The definition of exclusive breast-feeding was in accordance with the $\mathrm{WHO}^{(27)}$. In the present study, 4 weeks was taken to be 1 month, and mothers' understanding of 4 months being equivalent to 16 or 17 (calendar) weeks was clarified.

2. Meal episodes were defined by the time of the day the particular meal was consumed, and were differentiated as breakfast (consumed from the time of waking until 12.00 hours), lunch (consumed between 12.00 and 15.00 hours) and an evening meal (consumed between $>15.00$ and 18.00 hours). Any sweet/savoury food consumed as a course after a meal, including fruit purée and sweet varieties of commercially prepared infantspecific desserts, were also recorded, and combined with the foods consumed at the routine meal. Commercially prepared infant-specific foods refer to both readyprepared jarred infant foods and packets of dried infant foods, preparation of which requires addition of water/ milk. Home-prepared infant-modified meals refer to meals specifically prepared for infants, conducive to healthy eating guidelines and cooked without the use of 
added condiments, including sauces, gravy, sugar or salt. Home-prepared non-infant-modified meals were those that included unsuitable additions (salt, gravy, sauces, vegetable stock and sugar), and were served as meals to the family, as well as to the infant.

3. A 'snack' was defined as any sweet/savoury food offered to infants in between the routine meals. Data elicited on the usual type of snacks consumed by infants were open-ended responses, which were then categorised as infant rusks, yoghurt (infant/non-infant-specific), infantspecific baby biscuits, fruit/vegetables, chocolates, biscuits, bread and butter, crisps and ice-cream. Data on the weekly frequency of consumption of each listed snack were collected, and the infants were differentiated as those who consumed a snack $1-4$ or $>4$ times/week.

4. Mothers were questioned on the texture of the foods consumed by the infants at 6 months, and were provided with the following categories from which they had to choose: puréed (representing the first stage of weaning), soft/smooth, mashed/minced, soft/lumpy and roughly chopped.

5. 'Supplementary fluids' were defined as any fluid consumed by infants other than their main milk drink. Data elicited on the type of daily supplementary fluids were open-ended responses, which were then categorised as water, water and sugar mixture, fruit juice, diluted/undiluted baby juice, full-fat cows' milk and a separate category for non-recommended fluids for infants, including carbonated drinks and non-herbal tea. In accordance with the American Academy of Pediatrics guidelines that advise a daily limit of $120-180 \mathrm{ml}$ of fruit juice during infancy ${ }^{(28)}$, supplementary fluids were categorised as being consumed in volumes $<180 \mathrm{ml}$ or $\geq 180 \mathrm{ml} / \mathrm{d}$.

Table 1. Characteristics of the women and their infants in the $\leq 12$ ( $n$ 91) and $>12$ week $(n$ 309) weaning groups, and binary logistic regression analysis of the factors associated with weaning $\leq 12$ weeks

(Numbers, percentages, odds ratios and $95 \%$ confidence intervals)

\begin{tabular}{|c|c|c|c|c|c|c|c|c|c|c|}
\hline \multirow[b]{3}{*}{ Characteristics } & & & \multicolumn{4}{|c|}{ Weaning age* (weeks) } & \multirow[b]{3}{*}{$P$} & & & \multirow[b]{3}{*}{$P$} \\
\hline & \multicolumn{2}{|c|}{ Total $(n 400)$} & \multicolumn{2}{|c|}{$\leq 12$} & \multicolumn{2}{|c|}{$>12$} & & \multicolumn{2}{|c|}{ Adjusted $\dagger$} & \\
\hline & $n$ & $\%$ & $n$ & $\%$ & $n$ & $\%$ & & OR & $95 \% \mathrm{Cl}$ & \\
\hline \multicolumn{11}{|l|}{ Maternal age (years) } \\
\hline$\geq 35$ & 72 & 18 & 6 & 7 & 66 & 21 & & $1.0 \ddagger$ & & \\
\hline $25-34$ & 238 & 60 & 50 & 55 & 188 & 61 & & 3.57 & $1 \cdot 16,10 \cdot 94$ & 0.026 \\
\hline$\leq 24$ & 90 & 22 & 35 & 38 & 55 & 18 & 0.000 & 4.51 & $1.29,15.78$ & 0.018 \\
\hline \multicolumn{11}{|l|}{ Maternal education level§ } \\
\hline Third level/post graduate & 126 & 31 & 6 & 6 & 120 & 39 & & 1.0 & & \\
\hline Vocational/training course & 115 & 29 & 28 & 31 & 87 & 28 & & 4.93 & $1 \cdot 61,15 \cdot 1$ & 0.005 \\
\hline Primary and secondary & 159 & 40 & 57 & 63 & 102 & 33 & 0.000 & $6 \cdot 78$ & $2 \cdot 32,19 \cdot 77$ & 0.000 \\
\hline \multicolumn{11}{|c|}{ Smoking status during pregnancy } \\
\hline No & 307 & 77 & 52 & 57 & 255 & 83 & & $1 \cdot 0$ & & \\
\hline Yes & 93 & 23 & 39 & 43 & 54 & 17 & 0.000 & $1 \cdot 15$ & $0.56,2.36$ & 0.692 \\
\hline \multicolumn{11}{|l|}{ Birth weight $(\mathrm{kg})$} \\
\hline$>4$ & 65 & 16 & 9 & 10 & 56 & 18 & & 1.0 & & \\
\hline $3-4$ & 277 & 69 & 61 & 67 & 216 & 70 & & 0.76 & $0.27,2 \cdot 11$ & 0.604 \\
\hline$\leq 2.99$ & 58 & 15 & 21 & 23 & 37 & 12 & 0.010 & 1.73 & $0.63,4.74$ & 0.287 \\
\hline \multicolumn{11}{|c|}{$\begin{array}{l}\text { Mothers' reported sources of } \\
\text { advice on infant feeding: PHN }\end{array}$} \\
\hline No & 295 & 74 & 79 & 87 & 216 & 70 & & 1.0 & & \\
\hline Yes & 105 & 26 & 12 & 13 & 93 & 30 & 0.002 & 0.304 & $0.13,0.68$ & 0.004 \\
\hline \multicolumn{11}{|l|}{$\begin{array}{l}\text { Mothers' reported sources of } \\
\text { advice on infant feeding: } \\
\text { maternal grandmother }\end{array}$} \\
\hline No & 250 & 62 & 37 & 41 & 213 & 69 & & 1.0 & & \\
\hline Yes & 150 & 38 & 54 & 59 & 96 & 31 & 0.000 & $2 \cdot 26$ & $1 \cdot 21,4.25$ & 0.011 \\
\hline \multicolumn{11}{|c|}{$\begin{array}{l}\text { Mothers' antenatal reporting of } \\
\text { when infants should be } \\
\text { weaned onto solids (weeks)\| }\end{array}$} \\
\hline$>17$ & 167 & 44 & 16 & 19 & 151 & 51 & & $1 \cdot 0$ & & \\
\hline $13-17$ & 145 & 38 & 33 & 39 & 112 & 38 & & $2 \cdot 19$ & $1.04,4.61$ & 0.039 \\
\hline$\leq 12$ & 67 & 18 & 35 & 42 & 32 & 11 & 0.000 & $7 \cdot 33$ & $3.17,16.95$ & 0.000 \\
\hline \multicolumn{11}{|l|}{$\begin{array}{l}\text { Mode of infant feeding at } \\
12 \text { weeks postpartum }\end{array}$} \\
\hline 'Any' breast-feeding & 80 & 20 & 3 & 3 & 77 & 25 & & 1.0 & & \\
\hline Formula fed & 320 & 80 & 88 & 97 & 232 & 75 & 0.000 & 3.91 & $1.06,14.4$ & 0.040 \\
\hline
\end{tabular}

PHN, public health nurse.

* Univariate analyses using cross-tabulations and $\chi^{2}$ statistical tests to compare the differences between women and infants in the $\leq 12$ and $>12$ week weaning groups.

† Values are OR that were obtained from the final binary logistic regression model. The model was adjusted for maternal education level, age and smoking status during pregnancy, parity, infant birth weight and gestational age of infants at birth

$¥ 1.0$ denotes the reference group.

$\S$ Highest qualification attained.

$\| n 21$ missing values. 


\section{Statistical analyses}

The Statistical Package for the Social Sciences statistical software package version 17.0 (SPSS, Inc., Chicago, IL, USA) was used for all statistical analyses. Data were summarised using numerical descriptive statistics including means with standard deviations and medians with interquartile ranges. The relationship between categorical data was analysed using cross-tabulations and $\chi^{2}$ statistical tests. Statistical significance was taken at $P<0 \cdot 05$. The relationship between the actual age of infants at weaning (week) and mothers' antenatal reporting of when infants should be weaned (week) onto solids (two continuous variables) was explored using Spearman correlation coefficient for non-parametric data.

In accordance with the literature ${ }^{(19,29,30)}$, putative variables that were considered risk factors for early weaning were examined in the univariate analysis, including maternal/ paternal socio-demographic factors (using education level as a proxy for socio-economic status) and infant characteristics (parity, sex, gestational age at birth and birth weight). Factors related to maternal health behaviours during pregnancy were also examined, including smoking and alcohol consumption, as well as maternal postnatal employment-related factors such as timing of return to work postpartum $(\leq 18 v$. $>18$ weeks), employment status at 6 months postpartum (working full-time, part-time and non-working) and infant attendance to a child-minding facility during the first 6 months. Factors pertaining to infant feeding status during the first 6 months and mothers' reported sources of advice on infant feeding were all examined.

Binary logistic regression was then used to determine the variables that independently predicted early weaning with 'infants weaned at $\leq 12$ weeks' being the dependent variable. Multiple forward stepwise logistic regression was performed, and multivariate binary logistic regression models were developed based on a priori literature and the results obtained from the univariate modelling in the present study. Factors were retained in the model if they were significant at the $P<0.05$ criterion. The importance of each variable, adjusted for the others in its group, was assessed by the OR and $95 \% \mathrm{CI}$.

\section{Results}

Characteristics of the women and their infants ( $n$ 401) are detailed elsewhere ${ }^{(26)}$. A total of $304(76 \%)$ telephone and ninety-seven (24\%) face-to-face survey interviews were conducted at 6 months (mean time of follow-up: 24.73 (SD $0.43)$ weeks). At this stage, one infant $(0.2 \%)$ was exclusively breastfed and $400(99.7 \%)$ infants were established on solids. The characteristics of the women and their infants who were established on solids are described in Table 1. Altogether, $238(59 \%)$ mothers reported that they received professional advice on infant feeding during the first 6 months, mainly from the public health nurse (PHN) as reported by 217 $(91 \%)$ of these mothers.

\section{Timing of weaning and first weaning foods}

The median age of introduction to solid foods was 16 weeks (interquartile range $=14-17 \cdot 7$ ) (Fig. 1). In total, 286 infants $(71.3 \%)$ were weaned by 16 weeks (300 infants $(75 \%)$ were weaned by $\leq 17$ weeks) and ninety-one infants $(22.6 \%)$ had been weaned by 12 weeks postpartum. Weaning by 6 weeks was observed in fourteen (3.5\%) infants, while only twenty-four $(5.9 \%)$ infants were weaned beyond 20 weeks.

Commercially prepared puréed baby rice was reported as the most commonly used first weaning food by $239(60 \%)$ mothers, followed by an infant-specific, commercially prepared baby cereal reported by ninety-seven mothers $(24 \%)$. Home-prepared foods such as vegetable and fruit purées were used by twenty-three $(6 \%)$ and twelve $(3 \%)$ mothers, respectively, and gluten-containing cereals were used by three mothers $(<1 \%)$ as the first weaning foods. Infants consumed the first weaning food as a spoon feed on a daily basis for a mean of $11 \cdot 1$ (SD 9.2) d before another weaning food was introduced.

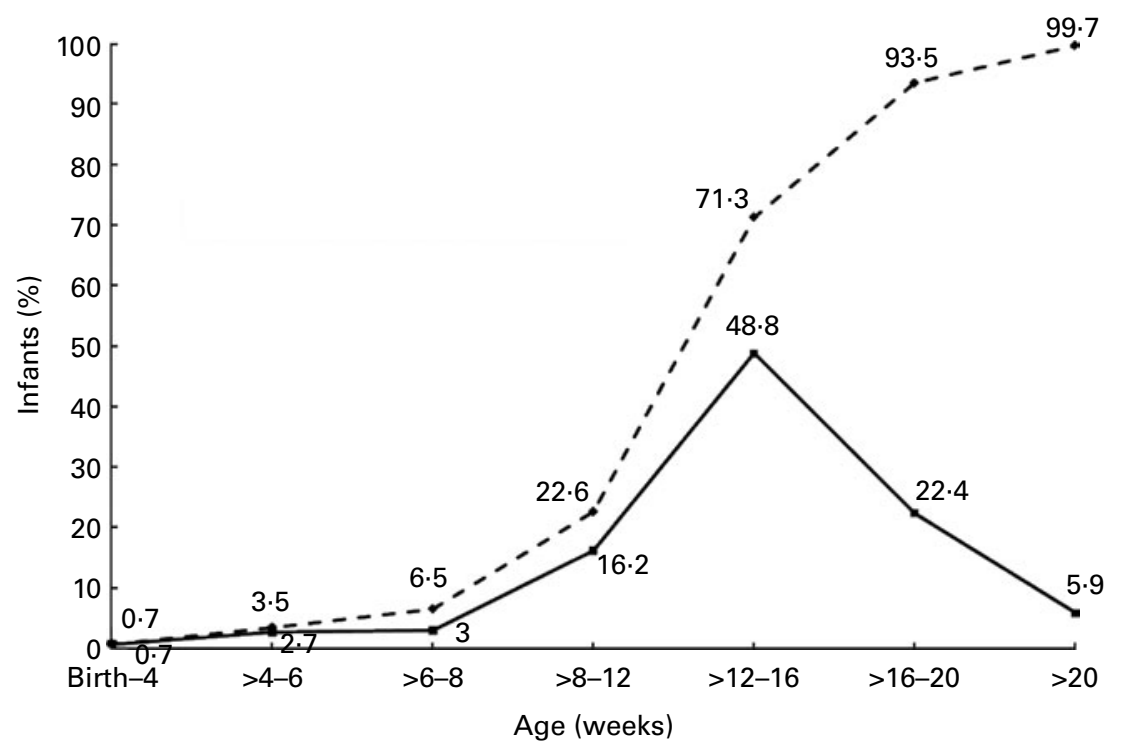

Fig. 1. Timing of the first introduction to solids during the first 6 months ( $n$ 401). (-๑-), Total weaned by that age; ( $\rightarrow-)$, weaned during each time period. 


\section{Determinants of early weaning}

In the univariate analysis, mothers who weaned their infants at $\leq 12$ weeks, compared with $>12$ weeks, were more likely to be $\leq 24$ years and educated to primary and secondary level, to have smoked during pregnancy and to have formula fed their infants at 12 weeks (Table 1). The two weaning groups ( $\leq 12 v$. $>12$ weeks) did not differ with regard to infant parity $(P=0 \cdot 146)$, sex $(P=0 \cdot 630)$, gestational age of the infant at birth $(P=0.718)$, infant attendance to a childminding facility during the first 6 months $(P=0.821)$, maternal alcohol consumption during pregnancy $(P=0 \cdot 308)$, employment status at 6 months $(P=0.605)$ or the timing of return to work postpartum $(P=0 \cdot 067)$ (data not shown).

The significant factors that independently predicted weaning at $\leq 12$ weeks, after adjustment, included mothers' antenatal reporting that infants should be weaned onto solids at $\leq 12$ weeks, formula feeding at 12 weeks and mothers' reporting of the maternal grandmother as the principal source of infant feeding advice (Table 1). Reporting of the PHN as the principal source of feeding advice was associated with weaning at $>12$ weeks. Furthermore, a significant positive correlation between mothers' antenatal reporting as to when infants should be weaned and actual weaning time postpartum was observed $\left(r_{\mathrm{s}} 0.317 ; P=0 \cdot 000\right)$, indicating that later weaning during the first 6 months was associated with later antenatal prediction of weaning time.

The maternal reasons that were most significantly associated with weaning at $\leq 12$ weeks $(P=0.000)$ included the maternal perception of infant hunger and sleep promotion (Table 2).

\section{Infant dietary patterns at 6 months}

Infant formula milk was consumed as the main milk drink by $386(96 \%)$ infants at 6 months ( $n 361$ consumed formula milk and solids; $n 25$ consumed a combination of formula milk, breast milk and solids). The mean daily volume of formula milk consumed by these infants was 828 (SD 226) $\mathrm{ml}$, with a mean of four (SD 0.99) formula feeds consumed in a $24 \mathrm{~h}$ period. Thirteen infants $(3.2 \%)$ were breastfed in addition to being fed with solids, with a mean of 5.92 (SD 1.8) breastfeeds offered to these infants in a $24 \mathrm{~h}$ period. One infant $(0.2 \%)$ in the total sample consumed solid foods in addition to full-fat cows' milk as the main milk drink in the absence of vitamin/mineral supplementation.

In addition to infants' main milk drink, a daily breakfast, lunch and evening meal were consumed by 385 (96\%), $381(95 \%)$ and $357(89 \%)$ of infants, respectively, while $235(59 \%)$ infants consumed at least one snack per $d$. The type of foods consumed by infants at the routine meals (breakfast, lunch and evening meal) is detailed in Figs. 2-4. A meat and vegetable or a vegetable-based meal tended to be consumed at lunch, rather than in the evening meal. Commercially prepared infant-specific foods featured as the most commonly consumed infant foods for breakfast (63.2\% consumed sweet varieties of infant-specific cereals) and lunch $(31 \%$ consumed a meat and vegetable-based meal), while sweet varieties of infant-specific desserts $(30.8 \%)$ were the most common foods consumed in the evening meal.

Infant rusks were the most frequently consumed weekly snack, followed by yoghurts and baby biscuits (Fig. 5). Snacks rich in refined sugar and salt, including chocolates, biscuits and crisps, were consumed $>4$ times/week by seven $(3 \%)$, nine $(4 \%)$ and nine $(4 \%)$ infants, respectively, while fruit/vegetables as a snack were consumed $>4$ times/week by twelve $(5 \%)$ infants. Few infants $(n 44)$ were reported to consume puréed textured foods at 6 months, while soft/ smooth, mashed/minced and soft/lumpy textured foods were consumed by $168(42 \%), 112(28 \%)$ and seventy-six $(19 \%)$ infants, respectively.

Of the $329(82 \%)$ infants who consumed supplementary fluids at 6 months, two $(0.6 \%)$, four $(1.2 \%)$ and twentythree $(7 \%)$ infants consumed fruit juice, carbonated drinks/ non-herbal tea and commercially prepared baby juices in

Table 2. Mothers' reported reasons for introducing solids to infants' diet during weaning at $\leq 12$ weeks $(n 91)$ and $>12$ weeks ( $n$ 309) postpartum*

(Numbers and percentages)

\begin{tabular}{|c|c|c|c|c|c|c|c|}
\hline \multirow[b]{3}{*}{ Mothers' reported reason(s) for introducing solids $†$} & & & \multicolumn{4}{|c|}{ Weaning age (weeks) } & \multirow[b]{3}{*}{$P$} \\
\hline & \multicolumn{2}{|c|}{ Total $(n 400)$} & \multicolumn{2}{|c|}{$\leq 12$} & \multicolumn{2}{|c|}{$>12$} & \\
\hline & $n$ & $\%$ & $n$ & $\%$ & $n$ & $\%$ & \\
\hline \multicolumn{8}{|l|}{ Maternal perception of infant hunger } \\
\hline Yes & 197 & 49 & 61 & 67 & 136 & 44 & \\
\hline No & 203 & 51 & 30 & 33 & 173 & 56 & 0.000 \\
\hline \multicolumn{8}{|l|}{ To promote sleep/'settle' the infant } \\
\hline Yes & 45 & 11 & 23 & 25 & 22 & 7 & \\
\hline No & 355 & 89 & 68 & 75 & 287 & 93 & 0.000 \\
\hline \multicolumn{8}{|l|}{$\begin{array}{l}\text { Maternal perception that the baby } \\
\text { was a 'big baby' and needed more } \\
\text { than breast/formula milk }\end{array}$} \\
\hline Yes & 21 & 5 & 9 & 10 & 12 & 4 & \\
\hline No & 379 & 95 & 82 & 90 & 297 & 96 & 0.031 \\
\hline
\end{tabular}

* 'Reasons for introducing solids' was an open-ended question, the specific responses to which were individually cross-tabulated with the dichotomous variable (weaned at $\leq 12$ weeks/weaned at $>12$ weeks).

$\dagger$ Mothers could indicate more than one reason for introducing solid foods. 


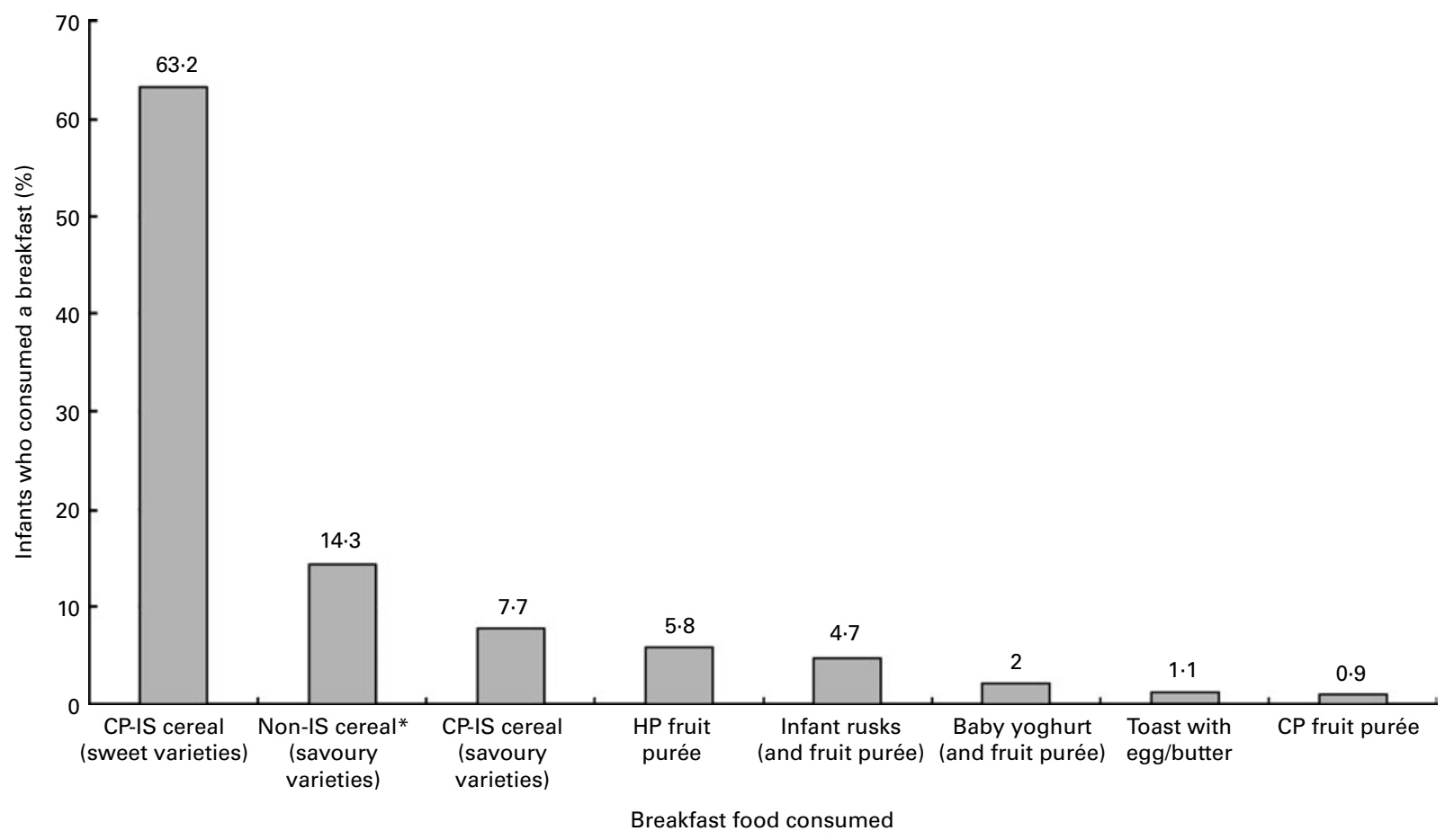

Fig. 2. Type of breakfast foods consumed by infants at 6 months $\left(n\right.$ 385). ${ }^{*}$ Includes maize-, wheat- and oat-based non-infant-specific cereals. CP-IS, commercially prepared infant-specific; HP, home-prepared.

volumes $\geq 180 \mathrm{ml} / \mathrm{d}$, respectively (Fig. 6). In total, 224 $(55.8 \%)$ infants had been introduced to a lidded beaker cup, with mothers reporting cooled boiled water and infant-specific baby juice as the main fluids consumed in the beaker cup by $105(47 \%)$ and ninety-four (42\%) of these infants, respectively.

\section{Maternal weaning practices}

Altogether, 141 mothers (35\%) added at least one extra condiment to the infants' weaning foods. Ordinary gravy, butter, sauces and vegetable stock were added by seventy-four (52\%), fifty-one (36\%), forty-seven (33\%)

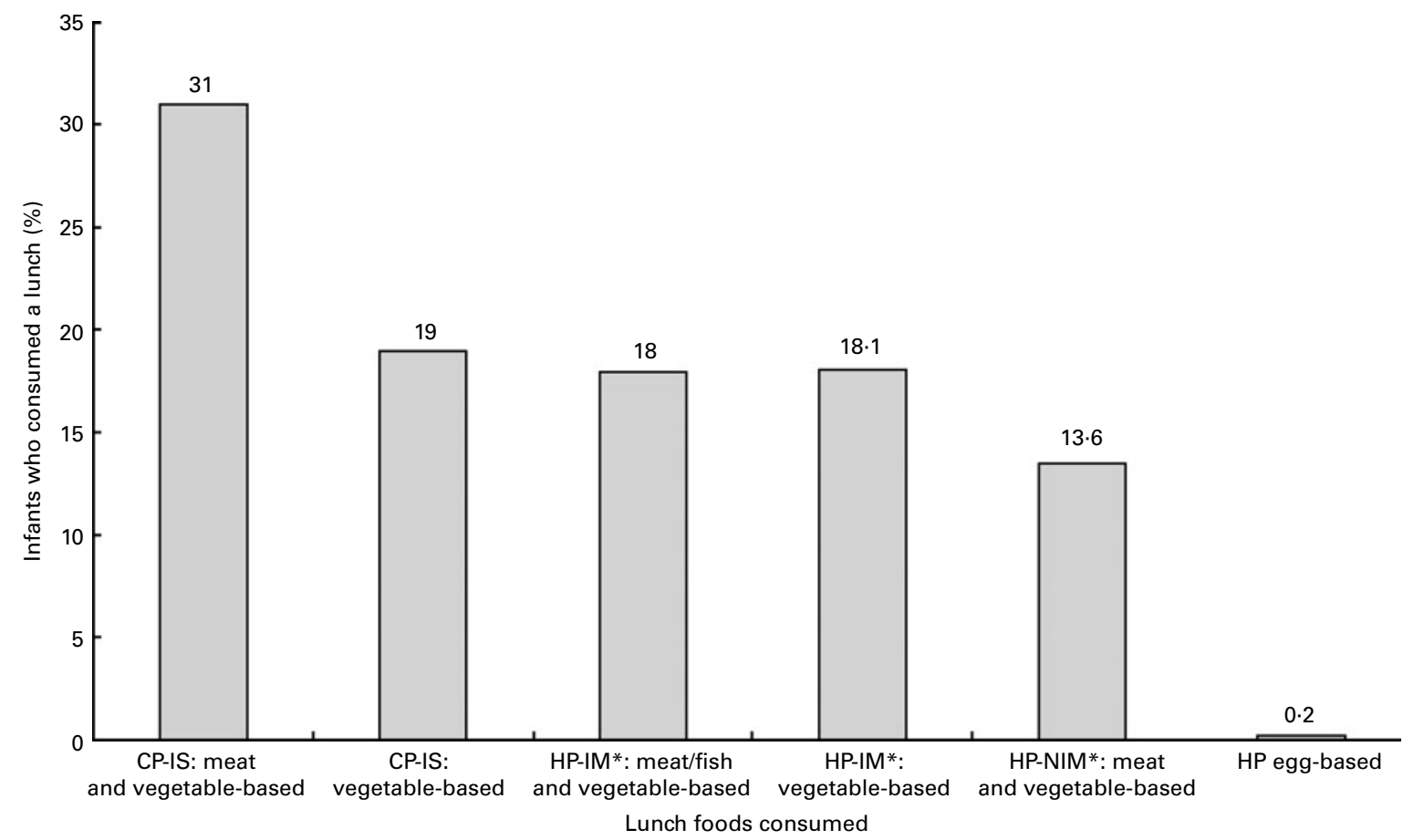

Fig. 3. Type of lunch foods consumed by infants at 6 months ( $n$ 381). *For definitions of HP-IM and HP-NIM, refer to 'explanatory measures' section of Subjects and methods. CP-IS, commercially prepared infant-specific; HP-IM, home-prepared infant-modified; HP-NIM, HP-non-infant-modified. 


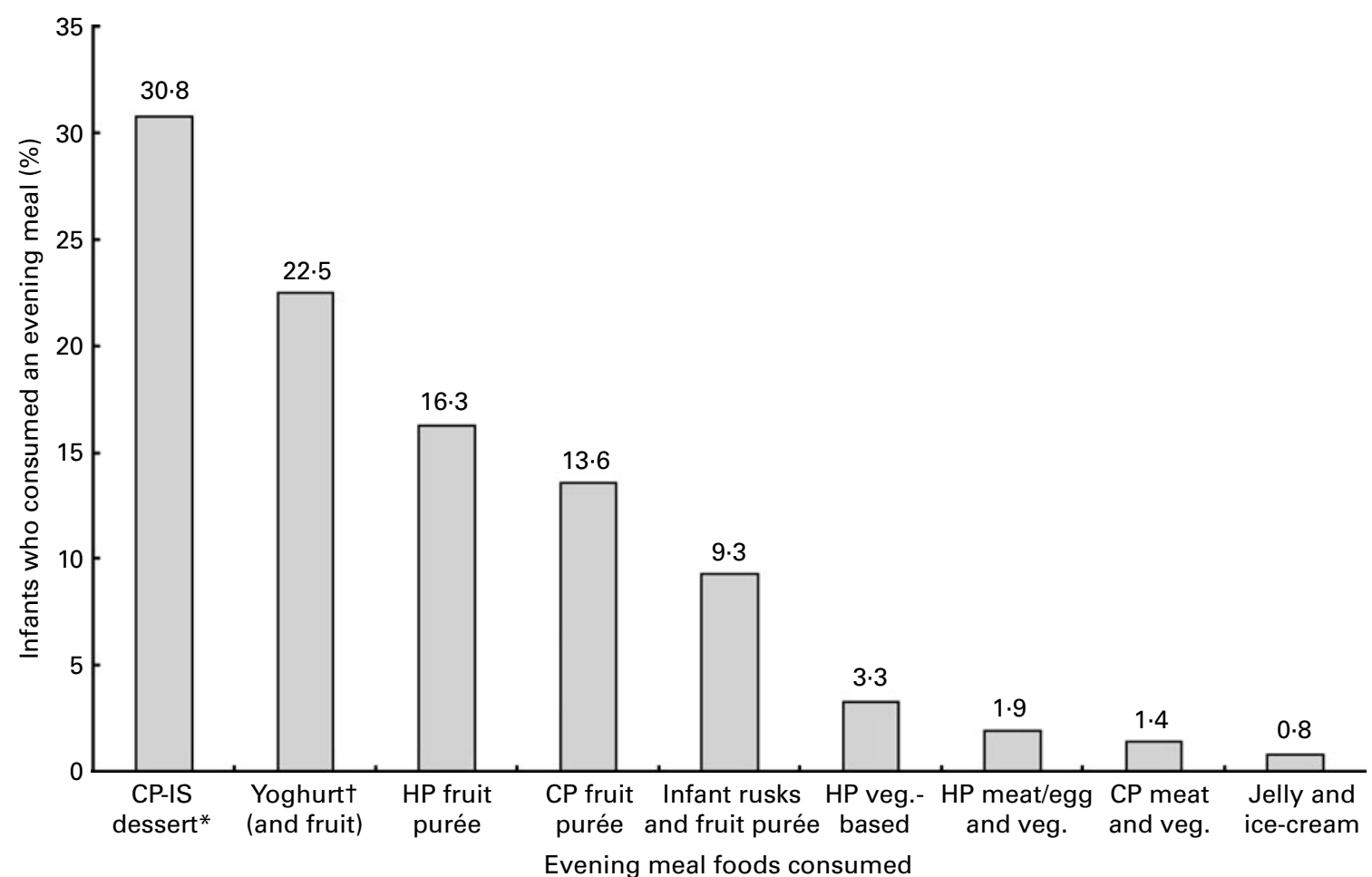

Fig. 4. Type of evening meal foods consumed by infants at 6 months ( $n$ 357). * Includes sweet dessert varieties for infants, e.g. apple crumble, custard, chocolate pudding desserts; †includes both infant-specific and non-infant-specific yoghurts. CP-IS, commercially prepared infant-specific; HP, home-prepared; Veg., vegetables.

and thirty-three $(23 \%)$ of these mothers, respectively, and table salt was added by five mothers $(3.5 \%)$. Sweet additions such as sugar/honey were added by forty-one mothers $(29 \%)$.

Eighteen mothers $(4.5 \%)$ in the total sample reported adding solid foods to their infants' bottled feeds, including baby rice $(n 7)$ and rusks ( $n$ 11), mainly to promote sleep, as reported by fifteen of these mothers.

Mothers who weaned their infants at $\leq 12$ weeks, compared with $>12$ weeks, were also more likely to have added nonrecommended condiments (ordinary gravy, butter, sauces, vegetable stock, salt and sugar/honey) to the weaning foods

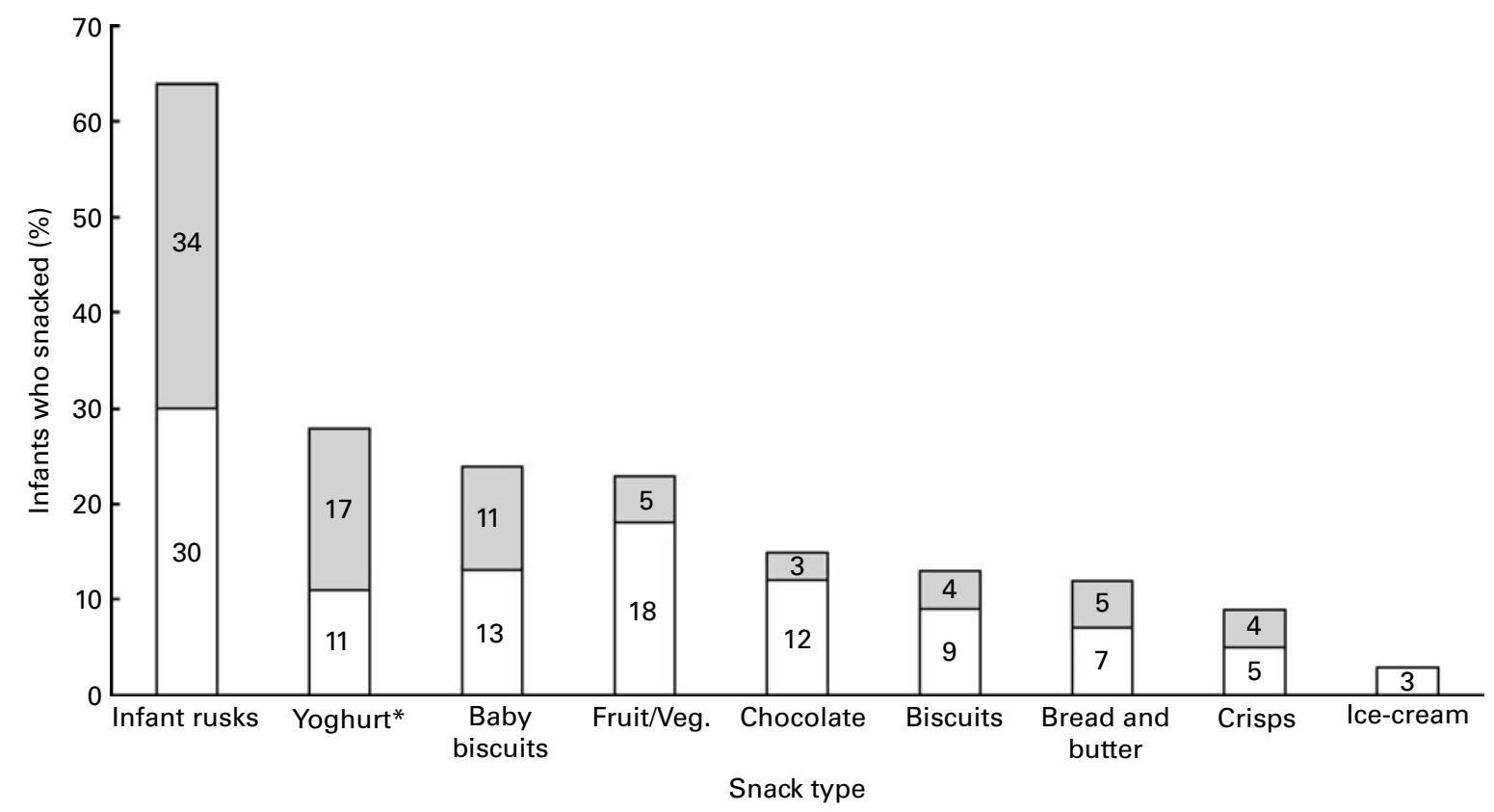

Fig. 5. Weekly snacking frequency of 6-month-old infants ( $n$ 235), with snacks consumed 1-4 ( $\square$ ) and $>4$ times/week ( $\square$ ); mothers could indicate more than one snack type. * Includes both infant-specific and non-infant-specific yoghurts. Veg., vegetables. 


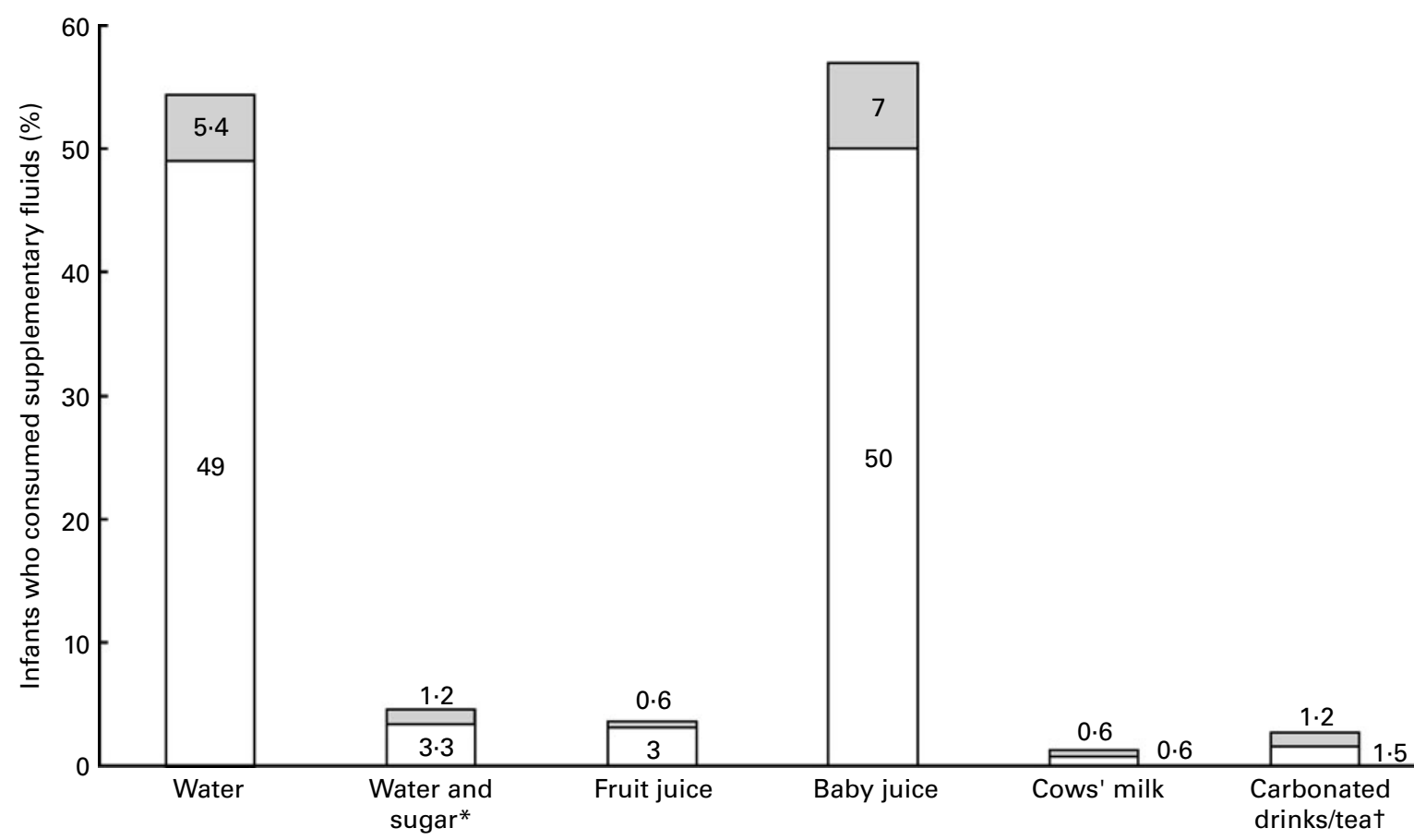

Fluid type

Fig. 6. Supplementary fluids consumed by 6 -month-old infants $(n$ 329) in volumes $<180(\square)$ and $\geq 180 \mathrm{ml} / \mathrm{d}(\square)$; mothers could indicate more than one type of supplementary fluid. ${ }^{*}$ Water and sugar mixture; $\dagger$ tea refers to non-herbal varieties.

$(P=0 \cdot 000)$, to have added solids to their infants' bottled feeds $(P=0.002)$ and to have offered their infants non-recommended snacks (chocolates, biscuits, crisps and ice-cream) $(P=0 \cdot 000)$ (data not shown). In the univariate analysis, mothers who added non-recommended condiments to the weaning foods and those who offered non-recommended snacks to their infants were more likely $(P=0.000)$ to be single mothers, $\leq 24$ years, smokers and educated to primary/secondary level, to have formula fed their infants from birth and to have reported the maternal grandmother as their principal source of advice on infant feeding.

\section{Discussion}

Significant deviations from the current weaning recommendations were demonstrated in the present study. Firstly, only one mother $(0.2 \%)$ complied with the $\mathrm{WHO}^{(3)}$ recommendation to exclusively breastfeed until 6 months. A national infant feeding study ${ }^{(31)}$ carried out in 1982 ( $n$ 1195) similarly reported that $<1 \%$ of mothers were exclusively breastfeeding at 6 months, indicating little improvement in exclusive breast-feeding rates over the past 24 years in Ireland. However, particularly low exclusive breast-feeding rates of 0.4 and $7 \%$ at 6 months have also been reported in robust studies from the UK $(n \text { 11 490) })^{(32)}$ and Norway $\left(n\right.$ 2383) ${ }^{(33)}$, respectively. Secondly, $75 \%$ of infants $(n$ 300) had been weaned onto solids before the minimum recommended weaning time of 4 months or 17 weeks $^{(7,8)}$, and of even greater concern is the finding that $22.6 \%$ of infants were prematurely weaned by 12 weeks postpartum. Although these figures indicate a marked shift towards later introduction of solids compared with previous Irish studies, which found that $68^{(34)}$ and $32 \%^{(35)}$ of mothers, respectively, had weaned their infants by 12 weeks, early weaning remains a concern not just in Ireland, but internationally ${ }^{(20,36)}$. Data obtained from the north-east of England ${ }^{(18)}$ and New Zealand ${ }^{(36)}$ similarly report that 21 and $20 \%$ of infants, respectively, are weaned onto solids by 12 weeks, while delayed weaning to 16 weeks has been demonstrated in $34.2 \%$ of infants in Italy ${ }^{(29)}$ and $34 \%$ of infants in Sweden ${ }^{(21)}$. The deleterious health consequences of early weaning have been well documented in the literature. Wright et al. ${ }^{(18)}$ showed that infants weaned onto solids before $3 v$. $>4$ months are at greater risk of diarrhoea and are more likely to visit their general practitioner between 6 weeks and 4 months. Weaning before $15 v$. $>15$ weeks has been shown to increase body fat and weight during childhood, as well as the probability of respiratory illness ${ }^{(14)}$.

In the present study, in addition to the early weaning, a high frequency of consumption of non-recommended snacks by infants ( $>4$ times/week), drinking of sugar-containing supplementary fluids in volumes $\geq 180 \mathrm{ml} / \mathrm{d}$ and frequent additions of salted and sugared condiments to weaning foods was observed. In particular, sweet varieties of commercially prepared infant-specific desserts (e.g. apple crumble and chocolate pudding desserts) and jelly with ice-cream were consumed by almost one-third of the infants $(31.6 \%)$ as the usual evening meal. In comparison, fewer infants consumed less sweetened foods in the evening meal, including yoghurt and/or fruit $(22.5 \%)$ and home-prepared fruit purée $(16.3 \%)$. Similarly, among the infants who consumed snack foods, $18 \%$ of the infants were found to consume sweet snack foods, including biscuits and chocolates $>4$ times/week in comparison with only $5 \%$ of the infants who consumed fruit and vegetables $>4$ times/week. According to the Committee on Medical Aspects of Food Policy ${ }^{(2)}$, added sugars provide energy in the infants' diet and increase the palatability of 
foods; however, they should be used sparingly, and where possible, unsweetened foods should be encouraged in preference to sugar-containing varieties. As dental caries development is associated with the amount and frequency of consumption of added sugars, best practice weaning guidelines recommend that infants consume sugar-containing foods and fluids either with or after a meal ${ }^{(2,8)}$. To promote optimal short- and long-term dental health, results of the present study point towards a need to highlight this recommendation in infant feeding literature, and in advice to parents.

Although the present study did not collect quantitative data on the food portions consumed, it appears that a significant proportion of 6-month-old infants in Ireland are regularly consuming foods rich in refined sugars, energy, saturated fats and salt, which have been suggested to adversely influence both later health ${ }^{(37,38)}$ and child food preferences ${ }^{(24)}$. Moreover, the regular consumption of such non-recommended foods during infancy may deleteriously affect the long-term compliance with healthy eating guidelines ${ }^{(39)}$, and may be a behavioural determinant of later overweight and obesity risk ${ }^{(40)}$. The present results are of further public health importance owing to the evidence that consumption of diets rich in salt during infancy cultivates a taste for salted foods ${ }^{(41)}$, and a high $\mathrm{Na}$ intake during early life could contribute to the risk profile for higher blood pressure later in life ${ }^{(38)}$.

Although cooled boiled water is the recommended supplementary drink for young infants ${ }^{(2,8)}$, a greater proportion of infants in the present study consumed baby juices $(57 \%)$ rather than water $(54.4 \%)$ as a supplementary fluid. Furthermore, thirty-three infants consumed sugar-containing supplementary fluids in volumes $\geq 180 \mathrm{ml} / \mathrm{d}$, an amount which is in excess of the recommended $120-180 \mathrm{ml} / \mathrm{d}$ set out in guidelines by the American Academy of Pediatrics ${ }^{(28)}$. Similarly, in the UK, Emmett et al. ${ }^{(42)}$ found that a greater proportion of 8-month-old infants ( $n$ 1178) consumed sugarcontaining supplementary fluids, including squashes/cordials $(55.8 \%)$ and fruit juice $(14.9 \%)$, in comparison with water $(19.7 \%)$. A disproportionate intake of sugar-containing fluids during the first 2 years may result in toddler diarrhoea ${ }^{(43)}$, non-organic failure to thrive ${ }^{(44)}$ and tooth decay ${ }^{(45)}$, and may lead to a decline in the consumption of milk and hence a decrease in the level of $\mathrm{Ca}$ in the diet ${ }^{(37)}$. Thus, our data strongly indicate that in infant feeding literature and while advising parents, greater emphasis should be placed on the appropriate use of supplementary fluids during infancy, as well as on snacking preferences and home preparation of infant foods, in line with infant feeding recommendations.

Comparable with other studies ${ }^{(12,19,30)}$, early weaning was significantly associated with socio-economic status in the present study. In agreement with our findings, maternal education level and age have been identified by other investigators as particularly influential socio-demographic determinants not only in relation to early weaning ${ }^{(19)}$, but also in relation to the types of supplementary fluids ${ }^{(46)}$ and foods consumed by infants ${ }^{(47)}$. Data obtained from the $\mathrm{USA}^{(47)}$ report that mothers ( $n$ 2515) who had a third-level college education were more likely to offer their infants fruit, rather than sweetened beverages, desserts and sweets, while results obtained from the present study indicate that mothers who were educated in a primary/secondary school were more likely to offer their infants non-recommended snacks, including chocolates, biscuits, crisps and ice-cream. To address the high prevalence of sub-optimal weaning practices and hence decrease inequalities in health, our data highlight that younger and less educated mothers who formula feed their infants and report the maternal grandmother as their principal source of advice on infant feeding represent a highly vulnerable group who deserve greater attention with regard to infant feeding support. Mothers who weaned their infants at $\leq 12$ weeks were also found to be more likely to carry out other sub-optimal weaning practices. Public health initiatives that aim to improve compliance with weaning recommendations and strategies to promote healthy infant feeding practices in Ireland should therefore target these high-risk groups.

In the present study, a significant association between mothers' antenatal reporting of when infants should be weaned and the timing when mothers' actually weaned was found. It is likely that mothers' antenatal reporting is closely associated with their antenatal expectation as to when they thought they would introduce solids to their infants' diet postpartum. Few studies have examined this antenatal and postnatal relationship; however, based on our findings, the effectiveness of public health campaigns or interventions that aim to correct mothers' misperceptions during the antenatal period and accurately inform both mothers and grandmothers-to-be of best infant feeding practices should be studied.

In the present study, the influential role of the PHN in delaying the introduction of solids was evident. In contrast, the negative impact of the maternal grandmother on mothers' weaning practices was also clearly demonstrated. Consistent with this finding, data obtained from Scotland report that mothers who weaned their infants at $<12 v$. $>12$ weeks were influenced by the opinions of the infants' maternal grandmother and friends ${ }^{(30)}$, similarly highlighting the importance of the social group on mothers' infant feeding practices. Compliance with traditional feeding practices that have been inter-generationally 'handed-down' has been shown to be more influential on mothers' practices than the professional advice received, and in addition, traditional feeding practices have the advantage of being readily available to mothers ${ }^{(48)}$. Although it is a possibility that mothers in the present study resorted to advice from the maternal grandmother due to the lack of weaning advice offered by the PHN, it has been shown that mothers who are aware of feeding recommendations are still likely to wean prematurely based upon influences from their social network ${ }^{(49)}$. According to Forsyth et $a l .{ }^{(12)}$, parents are not aware of the predicted harmful effects of early feeding with solids, and may perceive the practice to be beneficial to their infants. It has also been suggested that the potential threats to an infant's health may be stronger motivators for mothers than messages that point to the health benefits of delaying weaning to 4-6 months ${ }^{(50)}$. Although these findings raise awareness of the wide occurrence of sub-optimal weaning practices during the first 6 months among the health professionals in Ireland, effective and standardised strategies are needed to improve compliance with the weaning recommendations. The provision of detailed and standardised weaning information from the PHN no later than 12 weeks postpartum, in addition to increasing the impact of the PHN on mothers' weaning practices, is the potential area for the development of effective interventions to improve infants' diets. 
Given the finding that $41 \%$ of the mothers in the present study reported that they did not receive professional advice on weaning, there is a possibility that an overall deficiency in weaning information exists among these mothers. It may also have been the case that a proportion of mothers who did not comply with the weaning recommendations reported that they did not receive professional advice from the PHN or other health professionals during the first 6 months. Nonetheless, our data strongly suggest a need for the implementation of a structured national weaning policy that ensures the provision of specific weaning information to all parents, particularly, during the antenatal period.

There are a number of limitations to the present study. Firstly, this study is a prospective study that was conducted at a single centre, and therefore, it cannot be regarded as a population-based nationally representative study of weaning practices in Ireland. However, based on the literature available to date, no other prospective study done over the past decade has examined maternal weaning practices in Ireland using a large cohort of healthy term infants spanning over a 2-year period. Secondly, the accuracy of the maternal reporting of the infant's usual diet at 6 months, as well as the possibility of maternal recall bias in relation to the timing of weaning, must be considered. The short dietary history of the infant's usual diet at 6 months was reliant on mothers' memory at the time of the interview. Completion of an infant feeding logbook by mothers during the first 6 months may have increased the accuracy of the data collected. Recall bias is also a possibility with some mothers under- or/and over-estimating the foods and fluids consumed by infants in an effort to provide more socially desirable responses ${ }^{(51)}$. As the 6-month interview may have taken up to $30 \mathrm{~min}$ to complete, there may have also been a possibility that mothers gave less complete responses in an effort to complete the interview more quickly. Finally, in comparison with the telephone survey interviews, increased face-to-face contact with mothers during the home-visits may have contributed to a greater rapport with the mothers, resulting in potential response bias. Nonetheless, all the interviews were performed by an experienced investigator, and every effort was made to ensure consistent interview methods throughout the study population.

In conclusion, a high prevalence of sub-optimal weaning practices among mothers in Ireland, including premature weaning at $\leq 12$ weeks, was demonstrated in the present study. Initiating weaning advice to parents during the antenatal period may prove an effective measure to increase compliance with weaning guidelines. Crucially, weaning information requires greater specification with regard to healthy snack preferences, appropriate volumes of supplementary fluids and home-preparation of infant foods. In order to address the negative inter-generational influence of the maternal grandmother on weaning practices observed in the present study, intensive education, support and increased resources should be apportioned to younger and less educated mothers.

\section{Acknowledgements}

The authors thank the clinical and administrative staff of the CWIUH, Dublin 8, for their invaluable support and help in carrying out the present study. They also thank the 491 mothers who participated, and whose time and commitment to the study made its completion possible. The present study was funded by the Dublin Institute of Technology, Dublin 8, Republic of Ireland. R. C. T., J. M. K. and K. M. Y. were responsible for the study design and the interpretation of the results. R. C. T. was responsible for the recruitment and follow-up of the subjects, as well as for data collection and input, statistical analyses and preparation of the draft manuscript. J. M. K. was the project supervisor/coordinator, and was responsible for statistical analyses and manuscript revision. K. M. Y., M. S.-P. and M. J. W. were responsible for manuscript revision. The authors report no conflict of interest in relation to the present study.

\section{References}

1. Calvo EB, Galindo AC \& Apres NB (1992) Iron status in exclusively breast-fed infants. Pediatrics 90, 375-379.

2. Committee on Medical Aspects of Food Policy (1994) Weaning and the Weaning Diet. Report on Health and Social Subjects no. 45. London: HMSO, Department of Health.

3. World Health Organization (2001) Infant and Young Child Nutrition. Fifty-fourth World Health Assembly no. 54.2. Geneva: WHO.

4. Department of Health and Children (2003) Policy Change in Breastfeeding Guidelines. Dublin: Health Promotion Unit, Department of Health and Children. http://www.dohc.ie/press/ releases/2003/20030805.html (accessed November 2009).

5. Khakoo GA \& Lack G (2004) Introduction of solids to the infant diet. Arch Dis Child 89, 295.

6. Ward Platt MP (2009) Demand weaning: infants' answer to professionals' dilemmas. Arch Dis Child 94, 79-80.

7. Agostoni C, Decsi T, Fewtrell M, et al. (2008) Complementary feeding: a commentary by the ESPGHAN Committee on Nutrition. J Pediatr Gastroenterol Nutr 46, 99-110.

8. Food Safety Authority of Ireland (1999) Recommendations for a National Infant Feeding Policy. Dublin: Food Safety Authority of Ireland.

9. Kajosaari M (1991) Atopy prophylaxis in high-risk infants. Adv Exp Med Biol 310, 453-458.

10. Armentia A, Banuelos C, Arranz ML, et al. (2001) Early introduction of cereals into children's diets as a risk-factor for grass pollen asthma. Clin Exp Allergy 31, 1250-1255.

11. Fergusson DM, Horwood LJ \& Shannon FT (1990) Early solid feeding and recurrent childhood eczema: a 10-year longitudinal study. Pediatrics 86, 541-546.

12. Forsyth JS, Ogston SA, Clark A, et al. (1993) Relation between early introduction of solid food to infants and their weight and illnesses during the first two years of life. BMJ 306, 1572-1576.

13. Popkin BM, Adair L, Akin JS, et al. (1990) Breastfeeding and diarrheal morbidity. Pediatrics 86, 874-882.

14. Wilson AC, Forsyth JS, Greene SA, et al. (1998) Relation of infant diet to childhood health: seven year follow up of cohort of children in Dundee infant feeding study. BMJ 316, 21-25.

15. Northstone K, Emmett P, Nethersole F, et al. (2001) The effect of age of introduction to lumpy solids on foods eaten and reported feeding difficulties at 6 and 15 months. J Hum Nutr Diet 14, 43-54.

16. Hendricks KM \& Badruddin SH (1992) Weaning recommendations: the scientific basis. Nutr Rev 50, 125-133.

17. Wright C \& Birks E (2000) Risk factors for failure to thrive: a population-based survey. Child Care Health Dev 26, 5-16.

18. Wright CM, Parkinson KN \& Drewett RF (2004) Why are babies weaned early? Data from a prospective population based cohort study. Arch Dis Child 89, 813-816. 
19. Bolling K, Grant C, Hamlyn B, et al. (2007) UK Infant Feeding Survey 2005. London: The Information Centre. http://www.ic. nhs.uk/pubs/ifs2005 (accessed November 2009).

20. Schiess S, Grote V, Scaglioni S, et al. (2009) Introduction of complementary feeding in 5 European countries. $J$ Pediatr Gastroenterol Nutr 49, 1-8.

21. Hornell A, Hofvander Y \& Kylberg E (2001) Introduction of solids and formula to breastfed infants: a longitudinal prospective study in Uppsala, Sweden. Acta Paediatr 90, 477-482.

22. Harrod-Wild K (2007) Does childhood nutrition matter? J Fam Health Care 17, 89-91.

23. Devine C, Wolfe W, Frongillo E, et al. (1999) Life-course events and experiences: association with fruit and vegetable consumption in 3 ethnic groups. $J$ Am Diet Assoc 99, 309-314.

24. Skinner JD, Carruth BR, Bounds W, et al. (2002) Do food-related experiences in the first 2 years of life predict dietary variety in school-aged children? J Nutr Educ Behav 34, 310-315.

25. Ong KK, Emmett PM, Noble S, et al. (2006) Dietary energy intake at the age of 4 months predicts postnatal weight gain and childhood body mass index. Pediatrics 117, 503-508.

26. Tarrant RC, Younger KM, Sheridan-Pereira M, et al. (2010) The prevalence and determinants of breast-feeding initiation and duration in a sample of women in Ireland. Public Health Nutr 13, 760-770.

27. World Health Organization (1991) Indicators for Assessing Breastfeeding Practices, Division of Child Health and Development. Geneva: WHO.

28. American Academy of Pediatrics (2001) The use and misuse of fruit juice in pediatrics. Pediatrics 107, 1210-1213.

29. Giovannini M, Riva E, Banderali G, et al. (2004) Feeding practices of infants through the first year of life in Italy. Acta Paediatr 93, 492-497.

30. Alder EM, Williams FL, Anderson AS, et al. (2004) What influences the timing of the introduction of solid food to infants? Br J Nutr 92, 527-531.

31. McSweeney M \& Kevany J (1982) Infant Feeding Practices in Ireland: National Survey. Dublin: Health Education Bureau.

32. Pontin D, Emmett P, Steer C, et al. (2007) Patterns of breastfeeding in a UK longitudinal cohort study. Matern Child Nutr 3, 2-9.

33. Lande B, Anderson LF, Baerug A, et al. (2003) Infant feeding practices and associated factors in the first six months of life: the Norwegian infant nutrition survey. Acta Paediatr 92, $152-161$

34. Freeman VEA (1996) A longitudinal study of growth, feeding practices and iron status in healthy children from birth until age two years. PhD Thesis, Trinity College Dublin.
35. Twomey A, Kiberd B, Matthews T, et al. (2000) Feeding infants: an investment in the future. Ir Med J 93, 248-250.

36. Ford RP, Schluter PJ \& Mithell EA (1995) Factors associated with the age of introduction of solids into the diet of New Zealand infants. J Paediatr Child Health 31, 469-472.

37. Dennison BA (1996) Fruit juice consumption by infants and children: a review. J Am Coll Nutr 15, Suppl. 5, S4-S11.

38. Zinner S, McGarvey S, Lipsitt L, et al. (2002) Neonatal blood pressure and salt taste responsiveness. Hypertension 40, 280-285.

39. Cooke L (2007) The importance of exposure for healthy eating in childhood: a review. J Hum Nutr Diet 20, 294-301.

40. Baughcum AE, Burklow KA, Deeks CM, et al. (1998) Maternal feeding practices and childhood obesity. Arch Pediatr Adolesc Med 152, 1010-1014.

41. Bernstein IL (1990) Salt preference and development. Dev Psychol 26, 552-554.

42. Emmett P, North K, Noble S, et al. (2000) Types of drinks consumed by infants at 4 and 8 months of age: a descriptive study. Public Health Nutr 3, 211-217.

43. Hoekstra JH (1998) Toddler diarrhoea: more a nutritional disorder than a disease. Arch Dis Child 79, 2-5.

44. Smith MM \& Lifshitz F (1994) Excess fruit juice consumption as a contributing factor in nonorganic failure to thrive. Pediatrics 93, 438-443.

45. Holt RD (1997) Weaning and dental health. Proc Nutr Soc 56, $131-138$.

46. North K, Emmett P, Noble S, et al. (2000) Types of drinks consumed by infants at 4 and 8 months of age: sociodemographic variations. J Hum Nutr Diet 13, 71-82.

47. Hendricks K, Briefel R, Novak T, et al. (2006) Maternal and child characteristics associated with infant and toddler feeding practices. J Am Diet Assoc 106, S135-S148.

48. Daly A, MacDonald A \& Booth IW (1998) Diet and disadvantage: observations on infant feeding from an inner city. J Hum Nutr Diet 11, 381-390.

49. Anderson AS, Guthrie CA, Alder E, et al. (2001) Rattling the plate, reasons and rationales for early weaning. Health Educ Res 16, 471-479.

50. Horodynski M, Olson B, Arndt MJ, et al. (2007) Low-income mothers' decisions regarding when and why to introduce solid foods to their infants: influencing factors. J Community Health Nurs 24, 101-118.

51. Livingstone MB, Robson PJ \& Wallace JM (2004) Issues in dietary intake assessment of children and adolescents. $\mathrm{Br} J$ Nutr 92, S213-S222. 